\title{
OPEN A systematic review and meta-analysis of surgical morbidity of primary versus patch repaired congenital diaphragmatic hernia patients
}

Kim Heiwegen ${ }^{\bowtie}$, Ivo de Blaauw \& Sanne M. B. I. Botden

Large studies comparing the surgical outcome of primary versus patch repair in congenital diaphragmatic hernia (CDH) patients are rare. This study aims to evaluate the incidence of surgical complications in both types of CDH repair. PubMed, EMBASE, Cochrane and Web of Science were searched for peer-reviewed articles. Studies on CDH between 1991 and August 2020 were systematically screened and meta-analyses were performed. Primary outcomes of this review were: haemorrhage, chylothorax, recurrences and small bowel obstruction (SBO). A total of 6436 abstracts were screened, after which 25 publications were included (2910 patients). Patch repaired patients have a 2.8 times higher risk on developing a recurrence ( 20 studies) and a 2.5 times higher risk on developing a chylothorax (five studies). Moreover, they have a two times higher risk on developing a SBO. No studies could be included that evaluated the incidence of surgical haemorrhage between these patients. Although the quality of the studies was relatively low, patch repaired patients have a higher risk on developing a recurrence, chylothorax and small bowel obstruction. Large prospective studies are required to adjust for severity of disease, to reveal the true causative factors in order to minimize the risk on these surgical complications in both types of patients.

Treatment of congenital diaphragmatic hernia $(\mathrm{CDH})$ patients remains challenging. Surgical repair of $\mathrm{CDH}$ is required in order to relocate the herniated organs from the thoracic cavity to the abdomen and close the diaphragmatic defect. This repair is mostly performed by an open procedure, while there is ongoing discussion concerning the advantages and disadvantages of minimally invasive surgery ${ }^{1}$. Minimally invasive surgery has been associated with lower use of patch and higher incidence of recurrences ${ }^{2-4}$. The majority of the defects are repaired primarily (60-70\%), whereas the more severe cases (and largest defects) are repaired with the use of a patch ${ }^{5}$. Different types of patch materials have been used for closure of diaphragmatic defects. While some studies state that non-absorbable prosthetic patches, mainly PTFE (polytetrafluoroethylene), are preferred ${ }^{4,6}$, others prefer absorbable patches, such as collagen, or muscle-flap repair ${ }^{7}$ and others do not show a preference for type of material ${ }^{8}$. Although not many comparative studies evaluate primary versus patch repair, some complications have been highly associated with patch repair, such as chylothorax, which could lead to respiratory failure if not treated promptly ${ }^{9-11}$. Moreover, previous cohort studies have reported that patch repair is associated with higher rates of recurrences ${ }^{9,12}$. Because there is a lack of prospective and large studies on type of repair, this article provides a systematic review and meta-analysis to evaluate current evidence on the challenging topic of type of repair in $\mathrm{CDH}$ and the concurrent risk on surgical complications.

\section{Methods}

Search. A systematic literature search was performed in the databases PubMed, Web of Science, Cochrane and Embase for studies published between 1991 and August 2020 by the first author and a librarian. The studies were screened according to the Preferred Reporting Items for Systematic Reviews and Meta-Analysis (PRISMA) flow chart ${ }^{13}$. The search terms used were based on the subject ("congenital diaphragmatic hernia") and procedure ("patch repair" and "primary repair"). Search terms were restricted to title, abstract and keywords. When series 
from the same institution were found, the most recent study was included. Two authors (Sanne Botden, SB and Kim Heiwegen, KH) screened titles, abstracts and eventually full-text articles on inclusion and exclusion criteria independently. Final decision was based on discussion and consensus between these two authors. This review was registered on the international prospective register of systematic reviews (PROSPERO: CRD42019123189) ${ }^{14}$.

Selection criteria for included studies. Studies comparing primary repair versus patch repair in neonates with $\mathrm{CDH}$, reporting on minimally one of the outcomes were included. Exclusion criteria were studies focusing on Extracorporeal Membranous Oxygenation (ECMO) particularly, review articles, case reports, opinion papers, case series with $\leq 5$ patients in both compared groups and animal studies.

Data abstraction from included studies. The following data was extracted from each study separately; study characteristics (author names, year of publication, study design, study period, sample size and investigated type of repair), patient characteristics (age, gender, APGAR-score, side of defect, size of defect), method of reassigning patients to type of repair, peri-operative characteristics (surgical approaches in both groups, type of repair) and surgical morbidity. Surgical morbidity was stated as outcomes needing possible surgical intervention, which included the postoperative complications haemorrhage and recurrence, but also chylothorax and small bowel obstruction (SBO). The data was double checked by two authors independently (SB and $\mathrm{KH}$ ).

Methodological quality. Two authors (SB and $\mathrm{KH}$ ) independently assessed all articles on methodological quality according to the Grading of Recommendations Assessment, Development, and Evaluation (GRADE) system $^{15}$. The quality of evidence could be rated in four scores; high, moderate, low or very low. Downward rating was based on risk of bias, inconsistency, indirectness, imprecision (using optimal information size: OIS) and publication bias. The Risk of Bias in Non-Randomized Studies- of Interventions (ROBINS-I) tool was used to score studies on risk of bias, because no randomized studies were expected on this subject (Supplementary Information $)^{16}$.

Statistical analyses. The statistical analyses were performed using Review Manager (RevMan) 5.3 Software, provided by the Cochrane Collaboration (Oxford, England). Categorical data were analyzed using the Mantel-Haenszel method. Heterogeneity between studies was assessed using $\mathrm{I}^{2}$ (percentage of the variability in effect estimates due to heterogeneity rather than sampling error), with percentages of $30 \%$ considered low, $30-50 \%$ as moderate and $\geq 50 \%$ as considerable heterogeneity ${ }^{17,18}$. The random-effect model was used to assess the combined effect. Forests plots were used to graphically display risk ratios for categorical variables, including their $95 \%$ confidence interval. Publication bias was assessed for outcomes including more than ten studies by visual interpretation of a funnel plot (developed with RevMan). Sensitivity analyses were planned with exclusion of serious and or critical risk of bias according to ROBINS-I tool. Subgroup analyses, were performed on approach of repair (open versus minimally invasive (MIS) and on exclusion of patients treated before 2000 (because treatment strategies might have been different).

\section{Results}

Study selection. In total, 11,878 studies were identified by database searching, which is presented in the PRISMA Flow Diagram (Fig. 1). Manual screening did not lead to any new articles. Title and abstract screening were performed in 6436 studies, of which 96 remained eligible for full-text assessment. Another 71 were excluded due to several reasons (see Fig. 1), leading to inclusion of 25 studies. Studies which included registry data were excluded, because this could lead to double inclusion of patients ${ }^{19-21}$. For hernia recurrences 20 cohort studies were included, ten for SBO and five for chylothorax ${ }^{2,4,10,12,22-42}$. No studies were found reporting on rate of haemorrhage. By attempts to contact authors, additional data could not be obtained, leading to exclusion of one study ${ }^{43}$.

Characteristics of study. Study characteristics of the included quantitative studies are shown in Table 1. All included studies were cohort studies on CDH patients specifically $(n=2910)$. The mean rate of primary versus patch repaired patients was $57 \%(n=1704)$ versus $43 \%(n=1254)$. Different types of patch were used, although most studies (18/25) included used non absorbable patches such as PTFE $(n=16)$ or Polyester $(n=6)$. Collagen patches were used in five patients. The division of open versus MIS approach in the thirteen studies, which presented data on surgical approach, was $72.8 \%$ versus $27.2 \%$, while the remaining studies did not specify approach of repair specifically. There was a wide range of duration of follow-up, which ranged from four months till eleven years and was not specified in some of the studies.

Methodological quality. The ROBINS-I classification of the included studies are separately presented in the supplementary material. Three multicenter studies were found, of which two were national registries (Canada and Japan $)^{23,36,37}$. Ten studies were classified as serious or critical risk of bias, mostly due to unequal followup and selection bias. Moreover, confounding for disease severity factors, such as size of the defect or Apgar scores, was not possible or not present in most of the studies.

Haemorrhage. None of the included studies reported on surgical haemorrhage in primary versus patch repaired patients. One study by Brant et al. ${ }^{44}$ comparing primary versus patch and abdominal muscle flaps in $\mathrm{CDH}$ patients reported on haemorrhages, but was excluded from this review due to lack of required data. They reported that two patients in the prosthetic group had haemorrhages; one patient after day two, while the other 


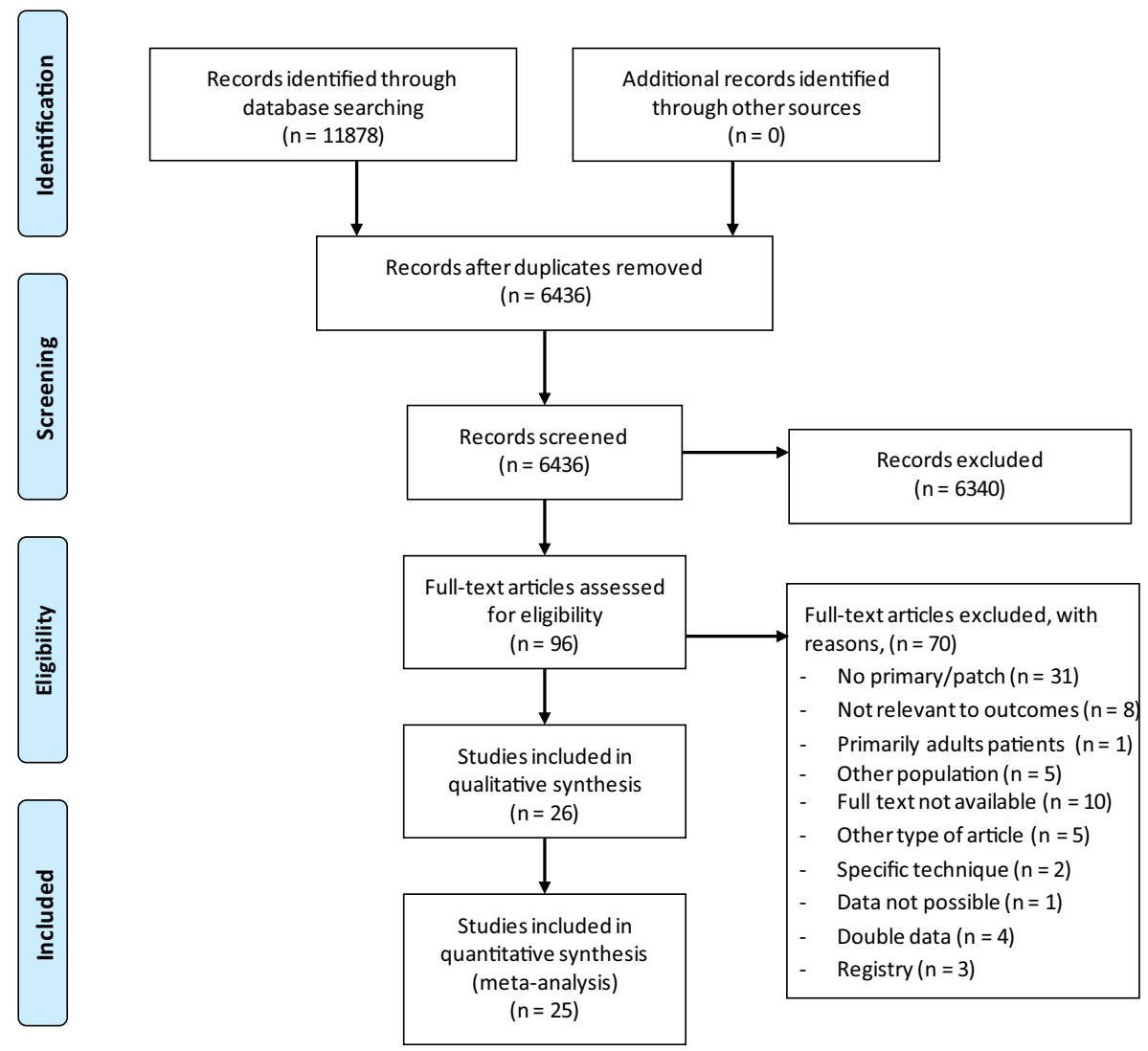

Figure 1. PRISMA flow diagram ${ }^{13}$.

required two reoperations for abdominal clot evacuation. None of the patients with a muscle flap had reported bleeding, though significance was not calculated.

Chylothorax. A meta-analysis on the post-operative complication chylothorax is shown in Fig. 2A. Five studies were included, which showed that the patch repaired patients have an increased risk (risk ratio $=2.47$ [1.25-4.87]) on developing a chylothorax compared to primary repaired patients. Hanekamp et al. ${ }^{27}$ included solely ECMO patients. Therefore, a subanalysis was performed without this study in which the difference remained statistically significant (risk ratio $=2.24[1.00-5.04]$ ). A sub analysis excluding patients treated before 2000 was not possible, as only two studies included solely patients after 2000 , of which one was scored as critical bias.

Recurrence. In total, 20 studies reported on recurrence rate for primary and patch repaired patients separately. The overall recurrence rate was $16.2 \%$ versus $5.8 \%$. Patients requiring patch repair have a 2.83 [2.16-3.71] greater risk on developing a recurrence (Fig. 2B). After exclusion studies with patients treated before $2000(n=9)$, the difference remained significant 2.47 [1.62, 3.77]. Sub-analyses were performed, if possible, on thoracoscopic versus open repaired patients. This showed that the difference for recurrence did not remain significant in minimally invasive repaired patients (RR 1.23 [0.65-2.32]). For the open repaired patients this was even higher than for both approaches combined (RR 3.60 [1.85-7.02]) (Fig. 2B).

Small bowel obstruction. In Fig. 2C the meta-analysis of the ten studies reporting on SBO is presented. The mean rate of SBO was $6.6 \%$ for primary repaired patient versus $12 \%$ of the patch repaired patients. Metaanalysis also shows that patch repaired patients are at greater risk of developing a SBO (risk ratio $=1.90[1.31-$ 2.76]). This remained significant in the subanalysis of the patients treated after $2000(n=5)$, risk ratio 2.03 [1.014.07].

Publication bias. Only a funnel plot of studies reporting recurrence could be made (Fig. 3), because more than ten studies could be included (see methods). Visual interpretation showed that there was no real asymmetry, indicating that small studies report on both positive and negative or no statistical significant effect of patches for this outcome. 


\begin{tabular}{|c|c|c|c|c|c|c|c|c|c|c|}
\hline \multirow{2}{*}{$\begin{array}{l}\text { Reference (first } \\
\text { author) }\end{array}$} & \multirow[b]{2}{*}{ Period } & \multirow[b]{2}{*}{ No. of patients } & \multicolumn{2}{|c|}{ Type of repair } & \multirow[b]{2}{*}{ Type of patch } & \multirow[b]{2}{*}{ Open/MIS ${ }^{* *}$} & \multicolumn{3}{|c|}{ Complications, n (\%) } & \multirow[b]{2}{*}{ Follow-up } \\
\hline & & & Primary & Patch $^{*}$ & & & Recurrence & SBO & Chylothorax & \\
\hline Al-Iede & $2000-2013$ & 85 & 65 & 20 & PTFE/Dacron & $71 / 14$ & $11(12.9)$ & & & $2 y$ \\
\hline Aydin & 2005-2016 & 119 & 28 & 91 & PTFE & 119/12(excl.) & $6(5.0)$ & & & $5 y a$ \\
\hline Costerus & 2008-2012 & 109 & 42 & 67 & PTFE & $34 / 75$ & $16(14.8)$ & & & $1 \mathrm{y}$ \\
\hline Fisher & 1990-2006 & 238 & 128 & 110 & PTFE & $231 / 7$ & $24(10.1)$ & & & \\
\hline Gander & 2006-2010 & 45 & 17 & 28 & PTFE & $19 / 26$ & $6(17.1)$ & & & $14 \mathrm{~m}^{\mathrm{a}}$ \\
\hline Gonzalez & 1997-2008 & 152 & 96 & 56 & Not specified & $137 / 15$ & & & $10(6.6)$ & \\
\hline Guner & 2004-2008 & 15 & 10 & 5 & Dacron & $0 / 15$ & $3(20)$ & & & $4-14 \mathrm{~m}$ \\
\hline Hanekamp & 1990-2000 & 89 & 48 & 41 & Not specified & Not specified & & & $9(10)$ & \\
\hline Jancelewicz (To) & $2000-2011$ & 157 & 115 & 42 & PTFE/SIS & $129 / 28$ & $23(15)$ & $12(8)$ & & \\
\hline Jancelewicz (SF) & $2000-2008$ & 99 & 42 & 57 & PTFE/SIS/flap & $94 / 5$ & $30(30.3)$ & $13(13.1)$ & & $4.7 \mathrm{y}^{\mathrm{a}}$ \\
\hline Janssen & 2000-2014 & 112 & 77 & 35 & PTFE & Not specified & $8(7.1)$ & $22(19.6)$ & & $7.3 y^{b}$ \\
\hline Jawaid & 1990-2010 & 118 & 81 & 37 & PTFE/SIS & $118 / 0$ & $2(1.8)$ & $2(1.8)$ & & $8.6 \mathrm{y}^{\mathrm{a}}$ \\
\hline Kamata & 1986-2000 & 33 & 18 & 15 & Not specified & Not specified & $4(12)$ & & & $11.4^{\mathrm{b}}$ \\
\hline Kamiyama & 1981-2008 & 198 & 109 & 89 & PTFE & Not specified & & & $11(5.6)$ & \\
\hline Keijzer & 2006-2008 & 46 & 18 & 28 & PTFE & $29 / 17$ & $4(15)$ & & & $1 y^{c}$ \\
\hline Laituri & 1994-2009 & 155 & 101 & 54 & $\begin{array}{l}\text { PTFE/Dacron/ } \\
\text { SIS/Alloderm }\end{array}$ & Not specified & $23(14.8)$ & $20(13)$ & & \\
\hline Lund & Not specified & 33 & 23 & 10 & PTFE & Not specified & $2(6.1)$ & & & $32 \mathrm{~m}^{\mathrm{b}}$ \\
\hline Mills & $2006-2010$ & 230 & 159 & 71 & Not specified & Not specified & & & $11(4.5)$ & \\
\hline Nagata & 2006-2010 & 180 & 112 & 68 & Not specified & $180 / 0$ & $21(11.6)$ & & & $3 y^{c}$ \\
\hline Riehle & 1993-1994 & 125 & 79 & 46 & PTFE & Not specified & $2(1.6)$ & $6(4.8)$ & & $27 \mathrm{~m}^{\mathrm{a}}$ \\
\hline St Peter & 1994-2004 & 81 & 57 & 24 & NA mesh, SIS & Not specified & $10(12.3)$ & $8(9.9)$ & & $7.95 \mathrm{y}^{\mathrm{a}}$ \\
\hline Suply & $2000-2016$ & 203 & 96 & 107 & PTFE, fibrine & $55 / 148$ & $14(6.9)$ & $8(3.9)$ & & \\
\hline Tsai & 1999-2010 & 149 & 75 & 74 & PTFE & $136 / 12$ & $7(8.6)$ & $5(3.4)$ & & $2 y^{a}$ \\
\hline Yokota & 1995-2013 & 74 & 49 & 25 & 'Artificial patch' & $74 / 0$ & $8(10.8)$ & $13(17.6)$ & & $50 \mathrm{~m}^{\mathrm{a}}$ \\
\hline Zavala & 2003-2009 & 65 & 29 & 36 & Not specified & Not specified & & & $7(10.8)$ & \\
\hline
\end{tabular}

Table 1. Study characteristics. ${ }^{\star}$ Patch including flap. ${ }^{\star \star}$ Open: abdominal or thoracotomy, MIS: Thoracoscopic or laparoscopic (Gonzalez, Jancelewicz $((\mathrm{To}), 1)$ ). ${ }^{\mathrm{a}}$ Median, ${ }^{\mathrm{b}}$ Mean, ${ }^{\mathrm{c}}$ Minimum, PTFE = polytetrafluorethylene, $\mathrm{m}=$ month(s), NA = non-absorbable, No. = total number, SIS = biological mesh (f.e. Surgisis ${ }^{\circledR}$ ) y=year(s).

Sensitivity analysis. Sensitivity analyses were performed on the outcomes excluding those studies with ROBINS-I scored as serious or critical. For chylothorax, only three studies were of low or moderate risk of bias, however the risk remained significant (2.81 [1.09-7.26]. After analysis, the risk on recurrence remained significantly higher for patch repaired patients (risk ratio $2.86[2.09,3.93]$ ), which was also the case for SBO $(1.93$ $[1.02,3.12)$.

\section{Discussion}

This systematic review reports on the difference in rate of surgical complications, including chylothorax, recurrence and $\mathrm{SBO}$ for primary versus patch repaired $\mathrm{CDH}$ patients. This study shows that patch repaired patients have a significantly higher risk on developing several surgical complications. This review is the first to evaluate the evidence on surgical morbidity in $\mathrm{CDH}$ patients, as shown in the overview of the current literature in Table 1. However, confounding for severity of defect or disease was not possible, mainly due to lack of data in reporting on the severity of the $\mathrm{CDH}$ in the publications on surgical complications used in this study. After 2006, the $\mathrm{CDH}$ registry produced a standardized classification (A-D) to describe the size of the defect ${ }^{45}$. Unfortunately, still little studies report on this defect size specifically, therefore confounding for severity of size of defect and its morbidity is not possible neither performed for most outcomes ${ }^{46}$. Patch repaired patients are often the patients with the largest defects, which is why patch repair is often seen and used as a surrogate marker for severity of disease. Although there have been many studies and technological advances in treatment with use of patches, the mortality rate still remains higher than primary repaired patients (26-35\% in patch repaired, versus $2.3-12.7 \%$ in primary repaired patients) ${ }^{47,48}$. However the severity of the disease is assumed to be linked with the size of the defect and subsequently the need for a patch to close the defect.

There are many types of patch material available. Although there remains ongoing discussion on the best type of material, most pediatric surgical centers use non-absorbable patches such as PTFE. The choice of material is also partly based on surgeon's preference and the availability in the different centers ${ }^{49}$. Some state that there is no real significant difference in for example recurrence rate or SBO between different types of material ${ }^{4,50}$. A review by Puglandia et al. ${ }^{6}$ recommended to use PTFE oversized/dome shaped patches to reduce recurrence rate after inclusion of 213 abstracts, however, with a level of evidence of IV, due to the lack of any high level of evidence studies reporting on the most preferable type of material. They also stated that it could also be caused by the technical factors of patch repair ${ }^{51}$. The most mentioned disadvantages of PTFE are the inability to grow 
A Chylothorax, forest plot

\begin{tabular}{|c|c|c|c|c|c|c|c|c|c|c|}
\hline Study or Subgroup & \multicolumn{2}{|c|}{ Patch } & \multicolumn{2}{|c|}{ Primary } & Weight & $\begin{array}{c}\text { Risk Ratio } \\
\text { M-H, Random, } 95 \% \mathrm{Cl}\end{array}$ & \multicolumn{4}{|c|}{$\begin{array}{c}\text { Risk Ratio } \\
\text { M-H, Random, } 95 \% \mathrm{Cl}\end{array}$} \\
\hline Gonzalez 2009 & 8 & 56 & 2 & 96 & $17.0 \%$ & $6.86[1.51,31.17]$ & & & & \\
\hline Hanekamp 2003 & 7 & 41 & 2 & 48 & $17.0 \%$ & $4.10[0.90,18.64]$ & & & & \\
\hline Kamiyama 2010 & 8 & 89 & 3 & 109 & $22.0 \%$ & $3.27[0.89,11.95]$ & & & & \\
\hline Mills 2012 & 4 & 71 & 7 & 159 & $24.9 \%$ & $1.28[0.39,4.23]$ & & & - & \\
\hline Zavala 2010 & 4 & 36 & 3 & 29 & $19.1 \%$ & $1.07[0.26,4.42]$ & & & & \\
\hline Total $(95 \% \mathrm{Cl})$ & & 293 & & 441 & $100.0 \%$ & $2.47[1.25,4.87]$ & & & & \\
\hline Total events & 31 & & 17 & & & & & & & \\
\hline $\begin{array}{l}\text { Heterogeneity: Tau } \\
\text { Test for overall effect }\end{array}$ & $\begin{array}{l}0.11 ; \mathrm{Chi}^{2} \\
\mathrm{z}=2.60 \mathrm{P}\end{array}$ & $\begin{array}{l}=4.89 \\
=0.00\end{array}$ & $\begin{array}{l}\text { df }=4(\mathrm{f} \\
09)\end{array}$ & $=0.3$ & $30 ; i^{2}=189$ & & 0.01 & $\begin{array}{c}0.1 \\
\text { Favours patch repair }\end{array}$ & $\begin{array}{c}10 \\
\text { Favours primary repair }\end{array}$ & 100 \\
\hline
\end{tabular}

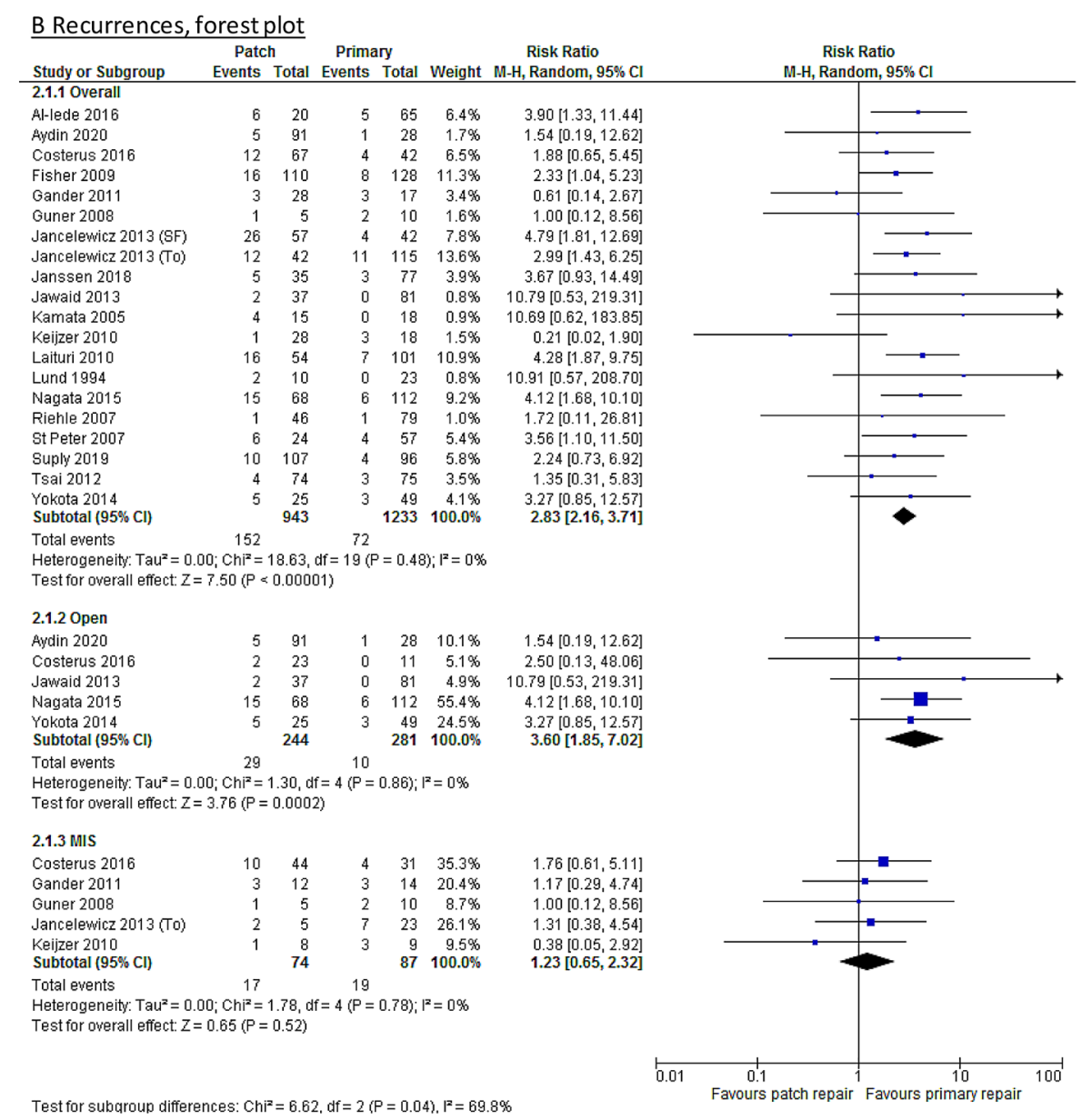

Test for subaroup differences: $\mathrm{Ch}^{2}=6.62, \mathrm{df}=2(\mathrm{P}=0.04), \mathrm{I}^{2}=69.8 \%$

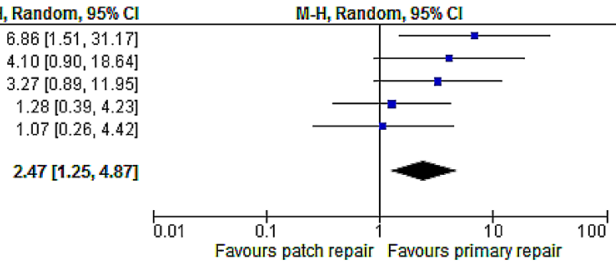

C Small bowel obstruction, forest plot

\begin{tabular}{|c|c|c|c|c|c|c|c|c|c|c|}
\hline Study or Subgroup & $\begin{array}{l}\text { Patc } \\
\text { Events }\end{array}$ & h & $\begin{array}{l}\text { Prima } \\
\text { Events }\end{array}$ & $\begin{array}{l}\text { ry } \\
\text { Total }\end{array}$ & Weight & $\begin{array}{c}\text { Risk Ratio } \\
\text { M-H, Random, } 95 \% \mathrm{Cl}\end{array}$ & & $\begin{array}{r}\text { Risk R } \\
\mathrm{M}-\mathrm{H}, \text { Rando } \\
\end{array}$ & $\begin{array}{l}\text { Ratio } \\
\text { om, } 95 \% \mathrm{Cl}\end{array}$ & \\
\hline Jancelewicz 2013 (SF) & 5 & 42 & 7 & 115 & $11.3 \%$ & $1.96[0.66,5.83]$ & & & 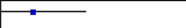 & \\
\hline Jancelewicz 2013 (To) & 12 & 57 & 1 & 42 & $3.4 \%$ & $8.84[1.20,65.38]$ & & & & \\
\hline Janssen 2018 & 10 & 35 & 12 & 77 & $24.0 \%$ & $1.83[0.88,3.83]$ & & & $=$ & \\
\hline Jawaid 2013 & 2 & 37 & 0 & 81 & $1.5 \%$ & $10.79[0.53,219.31]$ & & & & \\
\hline Laituri 2010 & 11 & 54 & 9 & 101 & $19.8 \%$ & $2.29[1.01,5.17]$ & & & $\Longrightarrow$ & \\
\hline Riehle 2007 & 2 & 46 & 4 & 79 & $5.0 \%$ & $0.86[0.16,4.51]$ & & & & \\
\hline St Peter 2007 & 5 & 24 & 3 & 57 & $7.5 \%$ & $3.96[1.03,15.26]$ & & & & \\
\hline Suply 2019 & 3 & 107 & 5 & 96 & $6.9 \%$ & $0.54[0.13,2.19]$ & & & & \\
\hline Tsai 2012 & 4 & 74 & 3 & 75 & $6.4 \%$ & $1.35[0.31,5.83]$ & & & $\rightarrow$ & \\
\hline Yokota 2014 & 6 & 25 & 7 & 49 & $14.0 \%$ & $1.68[0.63,4.47]$ & & & $\cdots$ & \\
\hline Total $(95 \% \mathrm{Cl})$ & & 501 & & 772 & $100.0 \%$ & $1.90[1.31,2.76]$ & & & 4 & \\
\hline Total events & 60 & & 51 & & & & & & & \\
\hline \multicolumn{6}{|c|}{$\begin{array}{l}\text { Heterogeneity: } \operatorname{Tau}^{2}=0.01 ; C_{1}^{2}=9.22, d f=9(P=0.42) ; I^{2}=2 \% \\
\text { Test for overall effect: } Z=3.37(P=0.0007)\end{array}$} & & 0.01 & $\begin{array}{c}0.1 \\
\text { Favours patch repair }\end{array}$ & $\begin{array}{c}10 \\
\text { Favours primary repair }\end{array}$ & 100 \\
\hline
\end{tabular}

Figure 2. (A) Forest plot - chylothorax. (B) Forest plot-recurrence. (C) Forest plot-small bowel obstruction. 


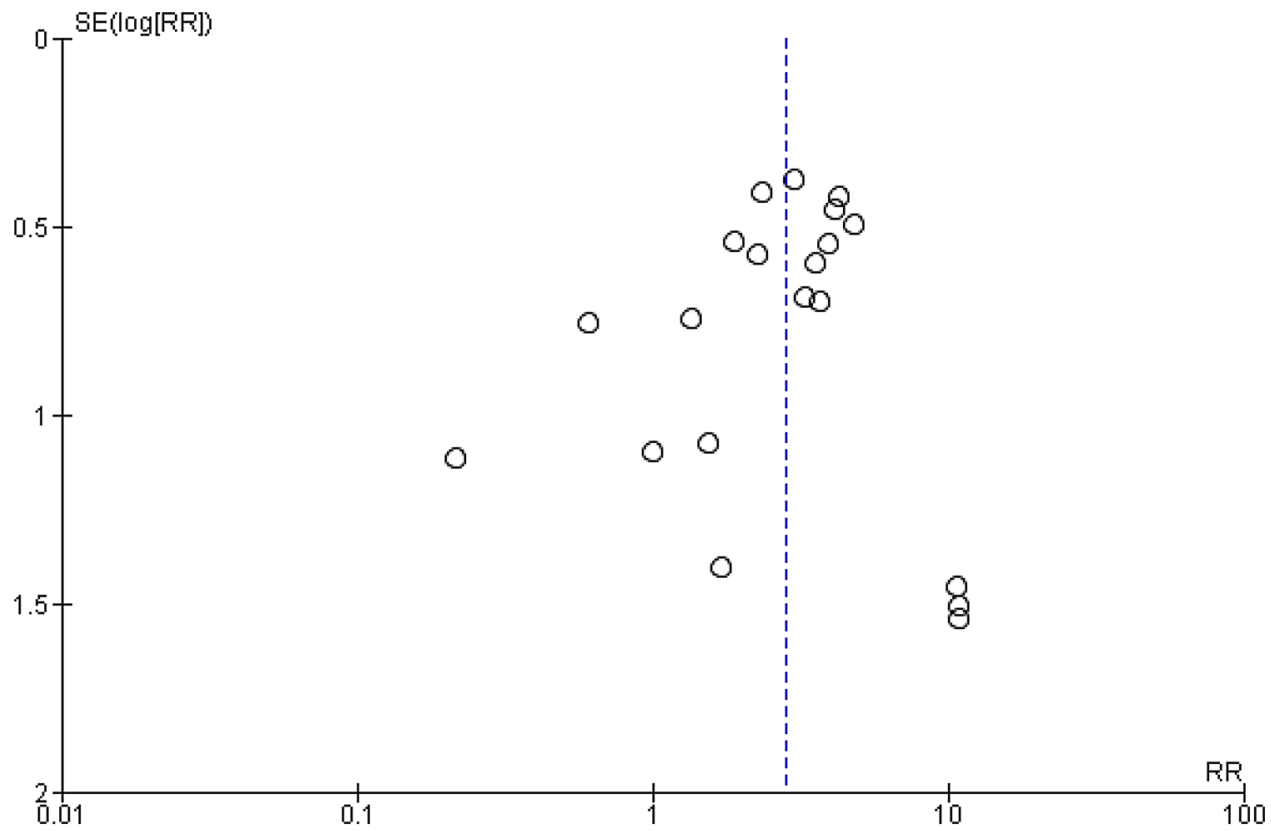

Figure 3. Funnel plot on publication of recurrence for primary versus patch repaired congenital diaphragmatic hernia patients.

with autologous diaphragmatic tissue $\mathrm{e}^{52}$ and formation of adhesions ${ }^{39}$. Also, as Tsai et al. ${ }^{4}$ stated complications may, to a greater extent, be due to technological factors rather than to the use of a patch itself. In this review, sub-analyses on type of patch material (and technological factors) were unfortunately not possible, due to the wide range of, not always specified, use in material in the studies.

Haemorrhage. No studies could be included describing the difference in rate of haemorrhage for primary or patch repaired patients. However, intra-operative bleeding rate seems to be higher after closure with a patch compared to primary repair ${ }^{40}$. Haemorrhage in $\mathrm{CDH}$ patients could be related to use of anticoagulants (for example in ECMO patients). These ECMO patients are the most severely affected patients, presumably with larger defects, often requiring a patch. Therefore, the contribution of solely the patch itself is often hard to distinguish. The fact that haemorrhage is not often reported in $\mathrm{CDH}$ studies as a primary or secondary outcome could be due to the fact that amount of blood loss is mostly an estimation from the treating surgeon and due to the retrospective nature of most $\mathrm{CDH}$ studies, this variable was probably not available for most authors.

Chylothorax. The incidence of $\mathrm{CDH}$ in surgically repaired patients with a chylothorax is $71 \%{ }^{53}$. Our review clearly shows that patch repaired patients are at greater risk on developing a chylothorax. Chylothorax is considered a serious complication in these already high risk neonates leading to electrolyte abnormalities, malnutrition and increased risk of infections due to immunodeficiency. It can subsequently lead to increased respiratory morbidity with longer periods of oxygen supply and hospitalization ${ }^{19,25,54}$. However, confounding for the development of chylothorax could be ECMO treatment, which has been suggested to be a predictor as well ${ }^{19}$. Sensitivity- or sub analyses could not be performed due to the small number of included studies, lack of data and more importantly the variety of criteria for chylothorax used in the studies.

Recurrence. Patch repaired patients had a higher risk on developing a recurrence, which is probably partly due to severity of disease. When correcting for approach of repair, the risk was not significant anymore for the MIS repaired patients, which could be caused by a selection bias in this group. Then again, different types of patch materials were used, for which confounding was not possible. There was a wide range of follow up in the studies, which was not always mentioned and, as a long term follow-up is relatively new in these patients could have influenced the incidence of recurrences ${ }^{28}$. However, of the 20 studies included for recurrences, 15 studies reported on length of follow-up, which was at least one year (Table 1), in which most recurrences are expected to occur $^{4,28,30}$. Above that, the manner and timing of diagnosis of a recurrence (for example the inclusion of asymptomatic patients or standard chest radiograph in standard follow-up) was often not specified ${ }^{37}$.

Small bowel obstruction. Ten studies reported on small bowel obstruction (SBO), divided by type of repair. Due to the wide range of follow-up (reported range 27 months to median 8.6 years as shown in Table $\left.1^{28,30,31,38-40}\right)$, the rate of SBO could be underestimated and might be higher after a longer follow-up ${ }^{55}$. Moreover, three studies did not report on the length of follow up ${ }^{12,29,42}$. Moreover, for this outcome specifically, it 


\begin{tabular}{|c|c|c|c|c|c|c|c|c|c|}
\hline \multicolumn{6}{|c|}{ Quality of evidence (grade) $)^{15}$} & \multicolumn{2}{|l|}{ Effect } & \multirow[b]{2}{*}{ Quality } & \multirow[b]{2}{*}{ Importance } \\
\hline $\begin{array}{l}\text { Number of } \\
\text { studies }\end{array}$ & Risk of bias* & Inconsistency & Indirectness & Imprecision & \begin{tabular}{|l|} 
Other \\
considerations
\end{tabular} & Relative $(95 \% \mathrm{CI})$ & Absolute & & \\
\hline \multicolumn{10}{|c|}{ Haemorrhage } \\
\hline 0 & - & - & - & - & - & - & - & - & - \\
\hline \multicolumn{10}{|l|}{ Chylothorax } \\
\hline 5 & Serious $^{1}$ & $\begin{array}{l}\text { No serious incon- } \\
\text { sistency }\end{array}$ & $\begin{array}{l}\text { No serious indi- } \\
\text { rectness }\end{array}$ & Serious $^{2}$ & None & $2.47[1.25-4.87]$ & $\begin{array}{l}57 \text { more per } 1000 \\
\text { (from } 10 \text { to } 149 \\
\text { more) }\end{array}$ & Low & Critical \\
\hline \multicolumn{10}{|l|}{ Recurrences } \\
\hline 20 & Serious & $\begin{array}{l}\text { No serious incon- } \\
\text { sistency }\end{array}$ & $\begin{array}{l}\text { No serious indi- } \\
\text { rectness }\end{array}$ & Serious $^{3}$ & None & $2.83[2.16-3.71]$ & $\begin{array}{l}107 \text { more per } 1000 \\
\text { (from } 68 \text { to } 158 \\
\text { more) }\end{array}$ & Low & Critical \\
\hline \multicolumn{10}{|c|}{ Small bowel obstruction } \\
\hline 10 & Serious & $\begin{array}{l}\text { No serious incon- } \\
\text { sistency }\end{array}$ & $\begin{array}{l}\text { No serious indi- } \\
\text { rectness }\end{array}$ & Serious $^{3}$ & None & $1.90[1.31-2.76]$ & $\begin{array}{l}59 \text { more per } 1000 \\
\text { (from } 20 \text { to } 116 \\
\text { more) }\end{array}$ & Low & Critical \\
\hline
\end{tabular}

Table 2. Methodological quality according to the Grading of Recommendations Assessment, Development, and Evaluation (GRADE) system. ${ }^{\star}$ Scored according to ROBINS-I tool ${ }^{16} .{ }^{1}$ Some studies scored as serious or critical risk of bias (due to selection bias and inadequate follow-up, according to ROBINS-I tool). ${ }^{2}$ Due to wide range of confidence interval and 'optimal information size (OIS)' not met (downgrade one level). ${ }^{3}$ OIS not met (downgrade one level).

would be interesting to confound for type of patch material used, which could lead to different rates of $\mathrm{SBO}^{30,39}$. Whatever the cause, patch repaired patients have a higher risk on developing a SBO, which should be closely monitored and early detected.

The outcomes of this review demonstrate the fact that a clinically significant amount of CDH patients after surgery remains at risk on developing several (possibly severe) morbidities, especially after patch repair. This is why a close long-term follow-up in a multidisciplinary clinic is required, though sufficient data on the ideal length and frequency of visits of follow-up has not been found yet. This is due to the fact that most studies are single center studies and include small numbers of patients ${ }^{56}$. In this review the focus was mainly on short term complications in these patients. Whatever the exact cause of the difference in surgical morbidity between these two groups of patients, this review supports the advice to at least monitor (high risk) patients during the first period of life.

Limitations of this review are the low quality of the studies (for example design, mostly retrospective) which led to small sample sizes, also due to the incidence of the disease and numbers of missing variables. One of most important limitations was the inability to adjust for contributing or confounding factors, such as severity of disease, subtype of $\mathrm{CDH}$ and type of patch material, which led to a low quality of evidence according to the GRADE system (Table 2). Therefore, further research could influence the impact of the estimated effects ${ }^{57}$. Another bias could be different treatment strategies between both centers and surgeons, because use of patch is often an intra-operative risk assessment. Because there are small number of studies regarding this subject, studies published from 1990 (including patients treated from 1980 onwards) were included. However, as treatment strategies possibly confounding the outcomes might have been different, sub-analyses were performed, if possible, to adjust for the treating period. This showed that in recurrence and SBO, outcomes were comparable. Sensitivity analyses showed that the outcomes remained similar after exclusion of low quality studies. The only type of study to conclude whether patch repair itself is an independent risk factor for surgical complications, would be a randomized controlled trial (RCT) which is not feasible. An RCT would not be feasible neither ethical because the larger defects (type D) cannot be closed by primary repair. For the very small defects (type A) it would be ethically difficult to repair it with a patch if it were possible to primary repair the defect without the patch. The best possible scenario would be to randomize cases where both treatment options are plausible, e.g. intermediate defects (type B). This leaves a small subset of patients and may make a RCT non-feasible. However, although an RCT is not achievable, it does not undermine the fact that especially for patch repaired patients, treatment needs to be improved to lower the almost two times higher risk on surgical complications.

\section{Conclusion}

Patch repaired congenital diaphragmatic hernia patients are at greater risk on developing surgical complications such as chylothorax, recurrence and small bowel obstruction. Current evidence is restricted to retrospective cohort studies and adjustment for morbidity severity is still not possible. Large prospective studies are required to collect adequate information to find the real causative factors. This could lead to new innovations that could minimize risk on surgical complications, especially in high risk $\mathrm{CDH}$ patients. 


\section{Data availability}

All data generated or analysed during this study are included in this published article.

Received: 13 December 2020; Accepted: 26 May 2021

Published online: 16 June 2021

\section{References}

1. Zani, A. et al. International survey on the management of congenital diaphragmatic hernia. Eur. J. Pediatric Surg. Zeitschrift fur Kinderchirurgie 26, 38-46. https://doi.org/10.1055/s-0035-156471 (2016).

2. Gander, J. W. et al. Early recurrence of congenital diaphragmatic hernia is higher after thoracoscopic than open repair: A single institutional study. J. Pediatr. Surg. 46, 1303-1308. https://doi.org/10.1016/j.jpedsurg.2010.11.048 (2011).

3. Lansdale, N., Alam, S., Losty, P. D. \& Jesudason, E. C. Neonatal endosurgical congenital diaphragmatic hernia repair: A systematic review and meta-analysis. Ann. Surg. 252, 20-26. https://doi.org/10.1097/SLA.0b013e3181dca0e8 (2010).

4. Tsai, J., Sulkowski, J., Adzick, N. S., Hedrick, H. L. \& Flake, A. W. Patch repair for congenital diaphragmatic hernia: Is it really a problem?. J. Pediatr. Surg. 47, 637-641. https://doi.org/10.1016/j.jpedsurg.2011.11.054 (2012).

5. Wilkinson, D. J. \& Losty, P. D. Management of congenital diaphragmatic hernia. Paediatr. Child Health 24, 23-26. https://doi.org/ 10.1016/j.paed.2013.07.001 (2013).

6. Puligandla, P. S. et al. Management of congenital diaphragmatic hernia: A systematic review from the APSA outcomes and evidence based practice committee. J. Pediatr. Surg. 50, 1958-1970. https://doi.org/10.1016/j.jpedsurg.2015.09.010 (2015).

7. Barnhart, D. C. et al. Split abdominal wall muscle flap repair vs patch repair of large congenital diaphragmatic hernias. J. Pediatr. Surg. 47, 81-86. https://doi.org/10.1016/j.jpedsurg.2011.10.023 (2012).

8. Grethel, E. J. et al. Prosthetic patches for congenital diaphragmatic hernia repair: Surgisis vs Gore-Tex. Journal of pediatric surgery 41, 29-33; discussion 29-33. https://doi.org/10.1016/j.jpedsurg.2005.10.005 (2006).

9. Moss, R. L., Chen, C. M. \& Harrison, M. R. Prosthetic patch durability in congenital diaphragmatic hernia: A long-term follow-up study. J. Pediatr. Surg. 36, 152-154 (2001).

10. Zavala, A. et al. Chylothorax in congenital diaphragmatic hernia. Pediatr. Surg. Int. 26, 919-922. https://doi.org/10.1007/s00383010-2677-3 (2010).

11. Losty, P. D. Congenital diaphragmatic hernia: Where and what is the evidence?. Semin. Pediatr. Surg. 23, 278-282. https://doi.org/ 10.1053/j.sempedsurg.2014.09.008 (2014).

12. Laituri, C. A. et al. Outcome of congenital diaphragmatic hernia repair depending on patch type. Eur. J. Pediatric Surg. Zeitschrift fur Kinderchirurgie 20, 363-365. https://doi.org/10.1055/s-0030-126193 (2010).

13. Moher, D., Liberati, A., Tetzlaff, J. \& Altman, D. G. Preferred reporting items for systematic reviews and meta-analyses: The PRISMA statement. PLoS Med. 6, e1000097. https://doi.org/10.1371/journal.pmed.1000097 (2009).

14. PROSPERO International Prospective Register of Systematic Reviews. https://www.crd.york.ac.uk/prospero/display_record.php? RecordID $=123189$.

15. Schünemann H, B. J., Guyatt G, Oxman A, editors. GRADE Handbook for Grading Quality of Evidence and Strength of Recommendations. https://gdt.gradepro.org/app/handbook/handbook.html.

16. Sterne, J. A. et al. ROBINS-I: A tool for assessing risk of bias in non-randomised studies of interventions. BMJ 355, i4919. https:// doi.org/10.1136/bmj.i4919 (2016).

17. Higgins, J. P. \& Thompson, S. G. Quantifying heterogeneity in a meta-analysis. Stat. Med. 21, 1539-1558. https://doi.org/10.1002/ sim.1186 (2002).

18. Higgins, J. P. T., G. S. e. Cochrane Handbook for Systematic Reviews of Interventions Version 5.1.0 [updated March 2011]. The Cochrane Collaboration, 2011. www.handbook.cochrane.org.

19. Levy, S. M., Lally, P. A., Lally, K. P. \& Tsao, K. The impact of chylothorax on neonates with repaired congenital diaphragmatic hernia. J. Pediatr. Surg. 48, 724-729. https://doi.org/10.1016/j.jpedsurg.2012.11.035 (2013).

20. Putnam, L. R. et al. Factors associated with early recurrence after congenital diaphragmatic hernia repair. J. Pediatr. Surg. 52, 928-932. https://doi.org/10.1016/j.jpedsurg.2017.03.011 (2017).

21. Tsao, K., Lally, P. A. \& Lally, K. P. Minimally invasive repair of congenital diaphragmatic hernia. J. Pediatr. Surg. 46, $1158-1164$. https://doi.org/10.1016/j.jpedsurg.2011.03.050 (2011).

22. Al-Iede, M. M., Karpelowsky, J. \& Fitzgerald, D. A. Recurrent diaphragmatic hernia: Modifiable and non-modifiable risk factors. Pediatr. Pulmonol. 51, 394-401. https://doi.org/10.1002/ppul.23305 (2016).

23. Costerus, S. et al. Thoracoscopic versus open repair of CDH in cardiovascular stable neonates. Surg. Endosc. 30, 2818-2824. https:// doi.org/10.1007/s00464-015-4560-8 (2016).

24. Fisher, J. C., Haley, M. J., Ruiz-Elizalde, A., Stolar, C. J. \& Arkovitz, M. S. Multivariate model for predicting recurrence in congenital diaphragmatic hernia. J. Pediatric Surg. 44, 1173-1179; discussion 1179-1180. https://doi.org/10.1016/j.jpedsurg.2009.02.043 (2009).

25. Gonzalez, R. et al. Chylothorax after congenital diaphragmatic hernia repair. J. Pediatric Surg. 44, 1181-1185; discussion 1185. https://doi.org/10.1016/j.jpedsurg.2009.02.021 (2009).

26. Guner, Y. S. et al. Thoracoscopic repair of neonatal diaphragmatic hernia. J. Laparoendosc. Adv. Surg. Tech. A 18, 875-880. https:// doi.org/10.1089/lap.2007.0239 (2008).

27. Hanekamp, M. N. et al. Does V-A ECMO increase the likelihood of chylothorax after congenital diaphragmatic hernia repair?. J. Pediatr. Surg. 38, 971-974 (2003).

28. Jancelewicz, T., Chiang, M., Oliveira, C. \& Chiu, P. P. Late surgical outcomes among congenital diaphragmatic hernia (CDH) patients: Why long-term follow-up with surgeons is recommended. J. Pediatr. Surg. 48, 935-941. https://doi.org/10.1016/j.jpeds urg.2013.02.005 (2013).

29. Jancelewicz, T. et al. Thoracoscopic repair of neonatal congenital diaphragmatic hernia (CDH): Outcomes after a systematic quality improvement process. J. Pediatr. Surg. 48, 321-325; discussion 325. https://doi.org/10.1016/j.jpedsurg.2012.11.012 (2013).

30. Janssen, S. et al. Factors related to long-term surgical morbidity in congenital diaphragmatic hernia survivors. J. Pediatr. Surg. 53, 508-512. https://doi.org/10.1016/j.jpedsurg.2017.05.032 (2018).

31. Jawaid, W. B., Qasem, E., Jones, M. O., Shaw, N. J. \& Losty, P. D. Outcomes following prosthetic patch repair in newborns with congenital diaphragmatic hernia. Br. J. Surg. 100, 1833-1837. https://doi.org/10.1002/bjs.9306 (2013).

32. Kamata, S. et al. Long-term follow-up of patients with high-risk congenital diaphragmatic hernia. J. Pediatr. Surg. 40, $1833-1838$. https://doi.org/10.1016/j.jpedsurg.2005.08.022 (2005).

33. Kamiyama, M. et al. Postoperative chylothorax in congenital diaphragmatic hernia. Eur. J. Pediatr. Surg. Zeitschrift fur Kinderchirurgie 20, 391-394. https://doi.org/10.1055/s-0030-1261956 (2010).

34. Keijzer, R. et al. Thoracoscopic repair in congenital diaphragmatic hernia: Patching is safe and reduces the recurrence rate. $J$. Pediatr. Surg. 45, 953-957. https://doi.org/10.1016/j.jpedsurg.2010.02.017 (2010).

35. Lund, D. P. et al. Congenital diaphragmatic hernia: The hidden morbidity. J. Pediatr. Surg. 29, 258-262; discussion 262-254 (1994). 
36. Mills, J., Safavi, A. \& Skarsgard, E. D. Chylothorax after congenital diaphragmatic hernia repair: A population-based study. J. Pediatr. Surg. 47, 842-846. https://doi.org/10.1016/j.jpedsurg.2012.01.031 (2012).

37. Nagata, K. et al. Risk factors for the recurrence of the congenital diaphragmatic hernia-report from the long-term follow-up study of Japanese CDH study group. Eur. J. Pediatr. Surg. Zeitschrift fur Kinderchirurgie 25, 9-14. https://doi.org/10.1055/s-0034-13954 $86(2015)$.

38. Riehle, K. J., Magnuson, D. K. \& Waldhausen, J. H. Low recurrence rate after Gore-Tex/Marlex composite patch repair for posterolateral congenital diaphragmatic hernia. J. Pediatr. Surg. 42, 1841-1844. https://doi.org/10.1016/j.jpedsurg.2007.07.009 (2007).

39. St Peter, S. D. et al. Abdominal complications related to type of repair for congenital diaphragmatic hernia. J. Surg. Res. 140, 234-236. https://doi.org/10.1016/j.jss.2007.03.018 (2007).

40. Yokota, K. et al. Surgical complications, especially gastroesophageal reflux disease, intestinal adhesion obstruction, and diaphragmatic hernia recurrence, are major sequelae in survivors of congenital diaphragmatic hernia. Pediatr. Surg. Int. 30, 895-899. https:// doi.org/10.1007/s00383-014-3575-x (2014).

41. Aydın, E. et al. When primary repair is not enough: A comparison of synthetic patch and muscle flap closure in congenital diaphragmatic hernia?. Pediatr. Surg. Int. 36, 485-491. https://doi.org/10.1007/s00383-020-04634-y (2020).

42. Suply, E. et al. Patch repair of congenital diaphragmatic hernia is not at risk of poor outcomes. J. Pediatr. Surg. 55, 1522-1527. https://doi.org/10.1016/j.jpedsurg.2019.10.021 (2020).

43. Casaccia, G., Crescenzi, F., Palamides, S., Catalano, O. A. \& Bagolan, P. Pleural effusion requiring drainage in congenital diaphragmatic hernia: Incidence, aetiology and treatment. Pediatr. Surg. Int. 22, 585-588. https://doi.org/10.1007/s00383-006-1706-8 (2006).

44. Brant-Zawadzki, P. B., Fenton, S. J., Nichol, P. F., Matlak, M. E. \& Scaife, E. R. The split abdominal wall muscle flap repair for large congenital diaphragmatic hernias on extracorporeal membrane oxygenation. J. Pediatr. Surg. 42, 1047-1050; discussion 1051. https://doi.org/10.1016/j.jpedsurg.2007.01.041 (2007).

45. Lally, K. P. et al. Standardized reporting for congenital diaphragmatic hernia-An international consensus. J. Pediatr. Surg. 48, 2408-2415. https://doi.org/10.1016/j.jpedsurg.2013.08.014 (2013).

46. Putnam, L. R. et al. Congenital diaphragmatic hernia defect size and infant morbidity at discharge. Pediatrics https://doi.org/10. 1542/peds.2016-2043 (2016).

47. Barriere, F. et al. One-year outcome for congenital diaphragmatic hernia: Results from the French National Register. J. Pediatr. 193, 204-210. https://doi.org/10.1016/j.jpeds.2017.09.074 (2018).

48. Brindle, M. E., Brar, M. \& Skarsgard, E. D. Patch repair is an independent predictor of morbidity and mortality in congenital diaphragmatic hernia. Pediatr. Surg. Int. 27, 969-974. https://doi.org/10.1007/s00383-011-2925-1 (2011).

49. Saxena, A. K. Surgical perspectives regarding application of biomaterials for the management of large congenital diaphragmatic hernia defects. Pediatr. Surg. Int. 34, 475-489. https://doi.org/10.1007/s00383-018-4253-1 (2018).

50. Nasr, A., Struijs, M. C., Ein, S. H., Langer, J. C. \& Chiu, P. P. Outcomes after muscle flap vs prosthetic patch repair for large congenital diaphragmatic hernias. J. Pediatr. Surg. 45, 151-154. https://doi.org/10.1016/j.jpedsurg.2009.10.024 (2010).

51. McHoney, M. Congenital diaphragmatic hernia, management in the newborn. Pediatr. Surg. Int. 31, 1005-1013. https://doi.org/ 10.1007/s00383-015-3794-9 (2015).

52. Gasior, A. C. \& St Peter, S. D. A review of patch options in the repair of congenital diaphragm defects. Pediatr. Surg. Int. 28, 327-333. https://doi.org/10.1007/s00383-012-3059-9 (2012).

53. Costa, K. M. \& Saxena, A. K. Surgical chylothorax in neonates: Management and outcomes. World J. Pediatr. 14, 110-115. https:// doi.org/10.1007/s12519-018-0134-x (2018).

54. Kavvadia, V., Greenough, A., Davenport, M., Karani, J. \& Nicolaides, K. H. Chylothorax after repair of congenital diaphragmatic hernia-risk factors and morbidity. J. Pediatr. Surg. 33, 500-502. https://doi.org/10.1016/s0022-3468(98)90097-5 (1998).

55. Heiwegen, K., de Blaauw, I., van Ling, J. \& Botden, S. Malrotation in congenital diaphragmatic hernia: Is it really a problem?. Eur. J. Pediatr. Surg. Zeitschrift fur Kinderchirurgie https://doi.org/10.1055/s-0039-1692165 (2019).

56. IJsselstijn HI. , et al. Defining outcomes following congenital diaphragmatic hernia using standardised clinical assessment and management plan (SCAMP) methodology within the CDH EURO consortium. Pediatr. Res. 84, 181-189. https://doi.org/10.1038/ s41390-018-0063-3 (2018).

57. Atkins, D. et al. Grading quality of evidence and strength of recommendations. BMJ 328, 1490-1490. https://doi.org/10.1136/bmj. 328.7454 .1490 (2004).

\section{Author contributions}

K.H. and S.B. wrote the main manuscript text and did the search for this manuscript. K.H. prepared the figures and tables. I.B. was responsible for the idea of this manuscript and wrote part of the manuscript text. All authors reviewed the manuscript.

\section{Competing interests}

The authors declare no competing interests.

\section{Additional information}

Supplementary Information The online version contains supplementary material available at https://doi.org/ 10.1038/s41598-021-91908-7.

Correspondence and requests for materials should be addressed to K.H.

Reprints and permissions information is available at www.nature.com/reprints.

Publisher's note Springer Nature remains neutral with regard to jurisdictional claims in published maps and institutional affiliations.

Open Access This article is licensed under a Creative Commons Attribution 4.0 International License, which permits use, sharing, adaptation, distribution and reproduction in any medium or
format, as long as you give appropriate credit to the original author(s) and the source, provide a link to the Creative Commons licence, and indicate if changes were made. The images or other third party material in this article are included in the article's Creative Commons licence, unless indicated otherwise in a credit line to the material. If material is not included in the article's Creative Commons licence and your intended use is not permitted by statutory regulation or exceeds the permitted use, you will need to obtain permission directly from the copyright holder. To view a copy of this licence, visit http://creativecommons.org/licenses/by/4.0/.

(c) The Author(s) 2021 